\title{
ENHANCEMENT OF DISSOLUTION CHARACTERISTICS OF CLOPIDOGREL BISULPHATE BY PRONIOSOMES
}

\author{
*1EMAN A. MAZYED, ${ }^{2}$ SHERIN ZAKARIA
}

1Department of Pharmaceutical Technology, Faculty of Pharmacy, Kaferelsheikh University, Kaferelsheikh, Egypt, ${ }^{2}$ Department of Pharmacology and Toxicology, Faculty of Pharmacy, Kaferelsheikh University, Kaferelsheikh, Egypt

Email: eman_mazyad@pharm.kfs.edu.eg

Received: 31 Oct 2018, Revised and Accepted: 09 Jan 2019

\section{ABSTRACT}

Objective: The present investigation aims to formulate and evaluate proniosomes of clopidogrel bisulphate for improving its dissolution characteristics.

Methods: The slurry method was used for the preparation of proniosomes of clopidogrel using cholesterol, sorbitan monostearate (Span 60) and maltodextrin as a carrier. Clopidogrel proniosomes were evaluated for their entrapment efficiency and in vitro drug release. The best formula (F1) that achieved maximum drug release was further evaluated by measurement of the angle of repose, morphological examination, determination of vesicle size, determination of zeta potential, Fourier transform infrared spectroscopy and differential thermal analysis. The in vivo behavior of the selected proniosomal formula (F1) was studied by measuring the antiplatelet activity in adult male mice.

Results: The entrapment efficiency of clopidogrel proniosomes was in the range of $83.04 \pm 1.99$ to $90.14 \pm 0.30$. \% drug released from proniosomal formulations was in the range of $79.73 \pm 0.35$ to $97.70 \pm 1.10 \%$ within $4 \mathrm{~h}$. Clopidogrel proniosomes significantly enhanced the in vitro release of clopidogrel compared with the plain drug that achieved $61.77 \pm 2.22 \%$ drug release. F1 significantly ( $\mathrm{p} \leq 0.001$ ) increased the bleeding time and bleeding volume and significantly $(\mathrm{p} \leq 0.05)$ prolonged prothrombin time and decreased prothrombin activity and increased the international normalized ratio (INR) compared to plain clopidogrel.

Conclusion: The present investigation introduced proniosomes as a promising carrier for clopidogrel that could enhance its dissolution and pharmacological effect.

Keywords: Clopidogrel, Maltodextrin, Proniosomes, Pharmacological effect

(C) 2019 The Authors. Published by Innovare Academic Sciences Pvt Ltd. This is an open access article under the CC BY license (http://creativecommons.org/licenses/by/4.0/) DOI: http://dx.doi.org/10.22159/ijap.2019v11i2.30575

\section{INTRODUCTION}

Clopidogrel bisulfate is a weak base that is known chemically as Methyl (S)- $\alpha$-(2chlorophenyl)-6,7di-hydrothieno[3,2-c]pyridine-5(4H)-acetate sulfate. Clopidogrel is a potent antiplatelet agent that is widely used for the prevention of coronary artery diseases and treatment of vascular thrombosis. However, it is of low aqueous solubility and therefore, it has low oral bioavailability (less than 50\%). Enhancement of solubility is of critical concern in improving dissolution rate and bioavailability. Recently, different nanotechnology techniques have been used to increase the dissolution rate and bioavailability of many drugs $[1,2]$.

Liposomes are phospholipid nano-vesicles that are used as drug carriers, but they suffer from several disadvantages like physical and chemical instability $[3,4]$. Therefore, special storage conditions and handling are required [5]. Niosomes are non-ionic surfactant vesicles that protect the drug against enzymatic degradation and improve drug permeability by their surface-active properties [6]. Niosomes are more stable chemically than liposomes, but they are also physically unstable due to the possibility of aggregation, fusion, and leakage of vesicles. Proniosomes are free-flowing powder form of niosomes [7]. Proniosomes could overcome physical instability problems of niosomes [8] and offer better convenience of storage and transportation. Following hydration, proniosomes are converted to niosomes $[9,10]$.

Though the oral drug delivery is the most common and preferred route of drug administration, failure of the conventional delivery of many drugs may happen due to poor drug absorption and highly fluctuated drug plasma levels. Lipid nano-vesicles like proniosomes have various advantages over conventional drug delivery systems because they act as drug reservoirs that enhance both drug solubilization and permeation. Moreover, proniosomes provide controlled drug release to deliver the effective dose of the drug to its target site $[8,9]$.

The aim of this study is to formulate proniosomes of clopidogrel by the slurry method for enhancement of dissolution and pharmacological effect of clopidogrel.

\section{MATERIALS AND METHODS}

\section{Materials}

Clopidogrel was a gift sample from the Egyptian International Pharmaceutical Industries Co., EPICO, Egypt. Cholesterol and maltodextrin were obtained from Sigma Chemical Co. (St. Louis, MO, USA). Potassium dihydrogen phosphate and sodium hydroxide were purchased from PureLab, USA. Sorbitan monostearate (Span 60) was purchased from Alpha Chemica, Mumbai, India. Ethanol and chloroform were obtained from El-Nasr Pharmaceutical Chemical Company, Cairo, Egypt.

\section{Methods}

\section{Preparation of clopidogrel proniosomes}

Clopidogrel proniosomes were formulated by the slurry method using maltodextrin as a carrier, table 1 . Accurately weighed amounts of clopidogrel, Span 60 and cholesterol were dissolved in chloroform/ethanol mixture $(2: 1 \mathrm{v} / \mathrm{v})$. The resultant solution is added to a round-bottom flask containing maltodextrin carrier to form the slurry. The organic solvents were removed using a rotary evaporator (Buchi rotavapor R-3000, Switzerland) that was adjusted to $70 \mathrm{rpm}$, at $45 \pm 2{ }^{\circ} \mathrm{C}$ under reduced pressure until the mass in the round-bottom flask become dry free-flowing product [13]. The formulated proniosomes were stored in wellclosed containers to be used for further studies. 
Table 1: Composition of clopidogrel loaded proniosomes

\begin{tabular}{lll}
\hline Formulation Code & Ratio $(\boldsymbol{\mu m o l})$ (Cholesterol: span60) & Maltodextrin (mg) \\
\hline F1 & $40: 210$ & 210 \\
F2 & $60: 190$ & 190 \\
F3 & $80: 170$ & 170 \\
F4 & $100: 150$ & 150 \\
F5 & $120: 130$ & 130 \\
F6 & $140: 110$ & 110 \\
F7 & $160: 90$ & 90 \\
\hline
\end{tabular}

*Each formulation containing clopidogrel bisulphate $98 \mathrm{mg}$ (which is equivalent to $75 \mathrm{mg}$ of clopidogrel base), * $1 \mathrm{~g}$ of Carrier (maltodextrin) per $1 \mathrm{mmol}$ of Span 60

\section{Preparation of niosomes from clopidogrel proniosomes}

The niosomal clopidogrel dispersion was directly prepared by hydrating the proniosomal powder with distilled water at $80{ }^{\circ} \mathrm{C} \pm 2{ }^{\circ} \mathrm{C}$ using a vortex mixer (BOECO, Germany) for $3 \mathrm{~min}$ [14]. The resulting niosomal dispersion was used for estimation of the entrapment efficiency. The niosomal dispersion was sonicated twice for $30 \mathrm{sec}$ using sonicator (Hielscher Ultrasonics, Germany) and stored at $4{ }^{\circ} \mathrm{C}$ for further studies.

\section{Determination of entrapment efficiency of clopidogrel proniosomes}

Entrapment efficiency of clopidogrel in proniosome-derived niosomes was done by centrifugation method. The niosomal dispersion prepared before by hydration of clopidogrel proniosomal powder was centrifuged at $6000 \mathrm{rpm}$ for $1 \mathrm{~h}$ at $4{ }^{\circ} \mathrm{C}$ [15] using a cooling ultracentrifuge (Biofuge, primo Heraeus, Germany). The whole supernatant was analyzed for the drug content by using UV spectrophotometer (Shimadzu U-V 1700, Japan). Encapsulation efficiency was calculated as follows:

$$
\mathrm{EE}(\%)=(\mathrm{A} 1-\mathrm{A} 2) \times 100 / \mathrm{A} 1
$$

Where $A 1=$ Initial amount of drug, $A-2$ Amount of drug in the supernatant

\section{In vitro release of clopidogrel proniosomes}

In vitro release of clopidogrel proniosomes and aqueous drug dispersion was performed using modified Franz di ffusion cells. Cellulose membrane was mounted between donor and receptor compartments. The receptor medium was phosphate buffer solution (PBS) pH 6.8 (containing 1\% sodium lauryl sulphate) that maintained at $37^{\circ} \mathrm{C} \pm 0.5^{\circ} \mathrm{C}$ and stirred at 50 $\mathrm{rpm}$. The proniosomal formulations and aqueous drug dispersion were loaded on the donor compartment. Samples were withdrawn at di fferent time intervals and replaced by the same amount of fresh bu ffer. The drug concentrations were determined using UV spectrophotometer. Triplicate experiments were performed. The results were expressed as mean values $\pm \operatorname{SD}[2,16]$.

The similarity factor test was used to compare the overall dissolution profiles and to determine the similarity in the pattern of drug release of plain drug and different proniosomal formulations [17]. The two preparations are said to be similar if the value of $f_{2}$ lies between 50 and $100 . f_{2}$ is calculated by the formula given below:

$$
f 2=50 . \log \left\{\left[1+\frac{1}{n} \sum_{t=1}^{n}(R t-T t)^{2}\right]^{-0.5}\right\} 100
$$

Where, $\mathrm{R}_{\mathrm{t}}$ and $\mathrm{T}_{\mathrm{t}}$ are percentages of drug dissolved at a specified time from the standard and test formulations respectively, $\mathrm{n}=$ no of sampling points.

\section{Kinetic treatment}

The release kinetics and mechanism of the in vitro release of clopidogrel proniosomes were studied by treating the data of drug release using different mathematical models as zero-order, firstorder kinetics and Higuchi model [18].

Zero-order model: $\mathrm{A}=\mathrm{K}_{\mathrm{o}} \mathrm{t}$

First-order model: $\ln (1-\mathrm{A})=-\mathrm{K}_{1} \mathrm{t}$
Higuchi model: $\mathrm{A}=\mathrm{KHt}_{1 / 2}$

Where: $A$ is the fraction of drug released in time $t, K_{0}$ is the rate constant of zero-order, $\mathrm{K}_{1}$ is the rate constant of first-order and $\mathrm{K}_{\mathrm{H}}$ is the rate constant of Higuchi diffusion model.

\section{Evaluation of the selected formula of clopidogrel proniosomes}

Clopidogrel proniosomal formulation that achieved the best in vitro release was evaluated by measurement of the angle of repose, Fourier-transform infrared spectroscopy (FTIR), differential thermal analysis (DTA), morphological examination and determination of vesicle size and zeta potential.

\section{Micromeritic properties}

The flow properties of the chosen proniosomal powder were determined by measurement of the angle of repose. The angle of repose of both maltodextrin and the chosen proniosomal powder was determined by the funnel method. A funnel was fixed at a certain height so that the outlet orifice of the funnel is $5 \mathrm{~cm}$ above a graph paper placed on a horizontal surface. Maltodextrin or proniosome powder was flowed down through the funnel until the apex of the powder pile just touched the funnel tip [19]. The angle of repose was estimated as follows:

$$
\operatorname{Tan} \theta=\mathrm{h} / \mathrm{r}
$$

( $\theta$ is the angle of repose, $h$ is the height of the powder pile and $r$ is the radius of powder pile).

\section{Photomicroscopic examination}

The formation of the noisomal vesicles upon hydration of the proniosomal powder was investigated by photomicroscopic examination. The selected proniosomal powder was spread on a glass slide and few microliters of distilled water $\left(80^{\circ} \mathrm{C} \pm 2{ }^{\circ} \mathrm{C}\right)$ were added dropwise. The morphology of the selected proniosomal powder (F1) and formation of the niosomal vesicles were observed under a light microscope (Coslabs micro, India) [8, 17].

\section{Scanning electron microscopy (SEM)}

The morphology of the chosen proniosomal formula derived niosomes was examined by the scanning electron microscope (SEM) (Jeol, JSM-6360, Japan). The optimized dispersion was firstly diluted with distilled water and dropped on the copper mesh. Few minutes after drying of excessive circumjacent liquid, 1\% phosphotungstic acid was added for a few minutes as a negative stain. The overflowed solution was sipped up and dried in the air $[18,19]$

\section{Vesicle size and zeta potential determination}

Determination of vesicle size and zeta potential was performed for investigating the colloidal characters of the chosen proniosomal formula (F1). The selected proniosomal formula was hydrated with distilled water $\left(80^{\circ} \mathrm{C} \pm 2{ }^{\circ} \mathrm{C}\right)$ for the formation of the niosomal vesicles. The niosomal dispersion was suitably diluted by distilled water. Then, laser scattering particle size analyzer (MALVERN ZETASIZER, MAL500999) was used for estimation of vesicle size and zeta potential [23].

\section{Fourier transform infrared spectroscopy (FT-IR)}

Fourier transform infrared spectroscopy was performed using FTIR spectrometer (FT-IR Shimadzu 8300 Japan). Samples of clopidogrel, Span 60, cholesterol, maltodextrin, plain proniosomes and the 
chosen clopidogrel proniosomal formula were used. All these samples were grounded and mixed with potassium bromide to form $\mathrm{KBr}$ pellets in a hydraulic press (Kimaya Engineers, Maharastra, India). The scanning range was $4000-400 \mathrm{~cm}^{-1}$ using PerkinElmer instrument (Spectrum RXI-5.31, UK) [1, 21].

\section{Differential thermal analysis (DTA) study}

DTA was used to investigate the change in the crystalline state of clopidogrel in the chosen proniosomal formula using differential thermal analyzer (Shimadzu DTA-50 module, Kyoto, Japan). The rate of heating was $10{ }^{\circ} \mathrm{C} / \mathrm{min}$. The samples of clopidogrel, Span 60 , cholesterol, maltodextrin, plain proniosomes, and the chosen clopidogrel proniosomal formula were heated in the range of $30-400{ }^{\circ} \mathrm{C}$ under dry nitrogen flow rate of $15 \mathrm{ml} / \mathrm{min}[22,23]$.

\section{In vivo study}

\section{Animals}

White male albino mice weighing 20-30 gm were used in this experiment. Mice were purchased from the National Research Center (Dokki, Giza, Egypt) and housed in a pathogen-free facility in sawdust bedded cages. The animal rooms were maintained at [25 \pm 2$]$ ${ }^{\circ} \mathrm{C}$ with $50 \%$ relative humidity and a $12 \mathrm{~h}$ light: dark cycle. All the tested mice were acclimatized under standard conditions in the animal house for at least two weeks prior to the experiments. The study protocol and animal use were approved by The Ethical Committee of Faculty of Pharmacy, Kaferelsheikh University. All the experimental procedures were performed in accordance with the recommendations of the ARRIVE guidelines [27] and comply with European Union Directive as 2010/63/EU [28] and the U. K. Animals (Scientific Procedures) Act, 1986 (ASPA) [29].

\section{Experimental protocol}

Mice were divided into 3 groups (10 mice each) the first group was treated with an aqueous dispersion of clopidogrel bisulfate (20 $\mathrm{mg} / \mathrm{kg}$ ) as a single oral dose (Standard group). The second group was gavaged with a single dose of clopidogrel proniosomal formula (F1) equivalent to $20 \mathrm{mg} / \mathrm{kg}$ orally (Test group). The third group was served as the control group. Mice in this group received only distilled water. Five mice of each group were used to evaluate platelet aggregation through measuring bleeding time and bleeding volume. The other five mice were integrated into the evaluation of coagulation activity markers [30].

\section{Platelet aggregation inhibition assay}

This study was done for studying the platelet aggregation inhibition effect of clopidogrel bisulfate and the selected clopidogrel proniosomal formula (F1). Five mice of each group were anesthetized using diethyl ether after $1 \mathrm{~h}$ of treatment. The tails of the anesthetized mice were cut (about $0.5 \mathrm{~cm}$ from the distal end of the tail) then embedded in tubes containing $2 \mathrm{ml}$ of phosphate saline buffer ( $\mathrm{PH} 7.4$ at $37^{\circ} \mathrm{C}$ ). The time until the bleeding stopped was detected using a stopwatch. The collected blood volume was then measured. The bleeding time and the bleeding volume were recorded $1 \mathrm{~h}$ and $3 \mathrm{~h}$ after oral administration of the plain drug and the selected clopidogrel proniosomal formula (F1) [31].

\section{Detection of coagulation profile}

$3 \mathrm{~h}$ after oral administration of clopidogrel and the selected clopidogrel proniosomal formula (F1), all mice were anesthetized with diethyl ether. Blood samples were collected via cardiac puncture and collected into tubes containing sodium citrate. The citrated plasma was used to evaluate the prothrombin time and activity.

Assay of prothrombin time and activity were done according to kits' instructions (EGY-CHEM for lab technology, Badr City, Egypt). Briefly, normal citrated plasma was added to tissue thromboplastin. The extrinsic clotting mechanism is then initiated forming a solid gel clot within a specified period of time. The test was made in triplicate and the results are the mean of three measurements. The international normalized ratio (INR) was calculated as the ratio between the mean of the prothrombin time of mouse plasma in seconds and mean of normal prothrombin time (MNPT) [29, 30].

\section{Statistical analysis}

Statistical analysis was performed using one-way analysis of variance (ANOVA) using Graph Pad Prism version 7 software. The differences were considered to be significant if $\mathrm{P}<0.05$.

\section{RESULTS AND DISCUSSION}

\section{Preparation of clopidogrel proniosomes}

Clopidogrel Proniosomes were prepared by the slurry method. Span 60 was chosen as the non-ionic surfactant that facilitates the formation of stable vesicles as it has a high phase transition temperature. Moreover, Span 60 could enhance the oral delivery of clopidogrel from the proniosomal vesicles [34]. Cholesterol was used to improve the encapsulation efficiency and stability of the prepared vesicles. Maltodextrin was chosen as the coating carrier [15]. Solvents used were chloroform and ethanol (2:1) because clopidogrel and lipids are soluble in this mixture and also ethanol is less toxic than methanol [11]. The ratio of cholesterol to Span 60 was changed from 40: 210 to160: 90 while keeping the total lipid constant at $250 \mu \mathrm{M}$ [13].

\section{Preparation of niosomes from clopidogrel proniosomes}

Clopidogrel niosomes were easily and directly formed after hydration of proniosome powder with distilled water at $80 \pm 2{ }^{\circ} \mathrm{C}$. Vesicular structures were formed over the surface of maltodextrin that may be attributed to swelling of the lipid bilayer that transformed into multilamellar vesicular structures with gentle agitation [15]. The multi-lamellar vesicles are further converted to unilamellar niosomal vesicles by sonication.

\section{Determination of entrapment efficiency of clopidogrel proniosomes}

The entrapment efficiency of clopidogrel proniosomes was in the range of $83.04 \pm 1.99$ to $90.14 \pm 0.30$, table 2 . High values of encapsulation efficiency may be attributed to the poor water solubility of clopidogrel and its dissolving in the lipid bilayers of niosomal vesicles [32, 33].

F4 showed the highest encapsulation efficiency of $90.14 \pm 0.30 \%$. As the ratio of cholesterol to Span 60 increased, the entrapment efficiency increased. That may be explained by the ability of cholesterol to increase the bilayer rigidity by intercalation between the bilayers of non-ionic surfactants [37]. However, very high cholesterol concentration was found to be of a lowering effect on the entrapment efficiency of the drug. This could be due to the fact that cholesterol beyond a certain level has the ability to disrupt the regular bilayered structure leading to decreasing drug entrapment [13]. Moreover, that may be attributed to competition between clopidogrel and cholesterol for packing in the limited sites in the bilayered structure of proniosomal vesicles thus excluding clopidogrel and disrupting the well-ordered bilayered structure $[35,36]$

\section{Table 2: Entrapment efficiency of clopidogrel proniosomes}

\begin{tabular}{ll}
\hline Formulation code & Entrapment efficiency \\
\hline F1 & $83.04 \pm 1.99$ \\
F2 & $84.07 \pm 3.02$ \\
F3 & $88.45 \pm 0.20$ \\
F4 & $90.14 \pm 0.30$ \\
F5 & $89.72 \pm 2.00$ \\
F6 & $88.23 \pm 0.23$ \\
F7 & $85.70 \pm 1.10$ \\
\hline
\end{tabular}

${ }^{*}$ Data are expressed as mean $\pm \mathrm{SD}, \mathrm{n}=3$ 
The ANOVA analysis of entrapment efficiency of proniosomal formulations showed that there was significant difference in entrapment efficiency between different clopidogrel proniosomal formulations as the ratio of cholesterol to Span 60 changed from 40: 210 to160: 90, table 3. F values were above the critical $F$ values and that made $P$ values $<0.05$ (threshold level). Thus, the null hypothesis $\left(\mathrm{H}_{0}\right)$ is rejected.

Table 3: ANOVA analysis of entrapment efficiency of clopidogrel proniosomes

\begin{tabular}{lllll}
\hline & SS & DF & MS & F \\
\hline Difference (between groups) & 140.4 & 6 & 23.41 & 8.86 \\
Difference (within groups) & 36.99 & 14 & 2.642 & 0.0004 \\
Total & 177.4 & 20 & & \\
\hline
\end{tabular}

\section{In vitro release of clopidogrel proniosomes}

From fig. 1, the in vitro release of clopidogrel proniosomal formulations was in the range of $79.73 \pm 0.35$ to $97.70 \pm 1.10$ within 4 h. It is observed that the results of entrapment efficiency are consistent with those of \% drug released, as F1 composed of cholesterol and Span 60 (40:210) molar ratio with the lowest entrapment efficiency showed the highest \% drug released. That was in good agreement with results reported by Singh et al.(2011) who concluded that niosomes that had the highest entrapment efficiency exhibited the lowest in vitro drug release due to decreasing drug efflux [36].

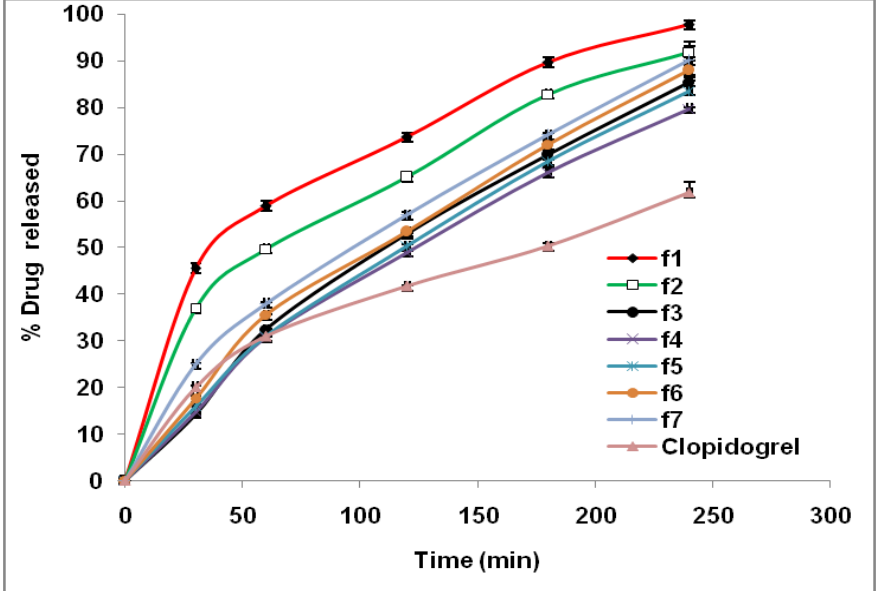

Fig. 1: In vitro release of plain clopidogrel and its proniosomal formulations, ${ }^{*}$ Data are expressed as mean $\pm S D, n=3$

It is concluded that as the molar ratio of cholesterol to surfactant increased, \%drug released decreased. That may be explained by a marked reduction in the efflux of the drug due to membrane stabilizing ability of cholesterol and its ability to abolish the gel-toliquid phase transition of niosomal systems [13].
However, a further increase in the amount of cholesterol beyond certain value caused disruption of the bilayered structure of the vesicles leading to higher drug release [20]. ANOVA analysis showed that increasing the molar ratio of cholesterol to Span60 from 40: 210 to 160: 90 resulted in significant $(\mathrm{p}<0.001)$ effect on $\%$ drug released, table 4 .

Table 4: ANOVA analysis of in vitro release of clopidogrel proniosomes

\begin{tabular}{lllll}
\hline & SS & DF & MS & F \\
\hline Difference (between groups) & 624.5 & 6 & 104.1 & 25.36 \\
Difference (within groups) & 57.47 & 14 & 4.105 & P value \\
Total & 682 & 20 & & \\
\hline
\end{tabular}

These results were in agreement with results reported by Shilakari et al.(2016) [40] who found that higher levels of cholesterol might compete with the drug for the packing space within the bilayer decreasing the stability of the bilayered vesicles.

An aqueous dispersion of plain drug achieved $61.77 \pm 2.22 \%$ drug release after $4 \mathrm{~h}$. Higher dissolution profile obtained with the proniosomal formulations than the plain drug might be due to an enhancement of solubility of clopidogrel by the non-ionic surfactant or due to change in clopidogrel structure from crystalline to amorphous state in proniosomal vesicles [31]. Moreover, it could be attributed to adsorption of lipid coat of proniosomal vesicles on maltodextrin increasing the effective surface area [13]. ANOVA analysis showed that incorporation of clopidogrel into proniosomes resulted in a significant increase in \% drug released compared to the plain drug $(\mathrm{p}<0.001)$, table 5 .

Table 5: ANOVA analysis of in vitro release of clopidogrel proniosomes in comparison to plain drug

\begin{tabular}{lllll}
\hline & SS & DF & MS & F \\
\hline Difference (between groups) & 2431 & 7 & 347.3 & 82.54 \\
Difference (within groups) & 67.32 & 16 & 4.208 & P value \\
Total & 2498 & 23 & & \\
\hline
\end{tabular}


The dissolution profile of different proniosomal formulations was compared with plain drug using the similarity factor test, table 6. The estimated values of $f_{2}$ were found to be less than 50 .
Therefore, it is obvious that there is a significant difference in drug release between different proniosomes in comparison to clopidogrel.

Table 6: Similarity factor test of clopidogrel proniosomes in comparison to plain drug

\begin{tabular}{ll}
\hline Formulation code & Similarity factor \\
\hline F1 & 24 \\
F2 & 30 \\
F3 & 41 \\
F4 & 47 \\
F5 & 44 \\
F6 & 39 \\
F7 & 37 \\
\hline
\end{tabular}

Based on the previous results, formula F1 that achieved the highest \% drug release after $4 \mathrm{~h}(97.70 \pm 1.10 \%)$ and had $83.04 \pm 1.99 \%$ encapsulation efficiency of the drug was chosen for further investigation.

\section{Kinetic treatment}

To find out the mechanism and order of drug release, data of in vitro release of clopidogrel formulations were fitted into different kinetic models, table 7 . The correlation coefficient values indicated that the profile of drug release followed Higuchi diffusion model. These results indicated that the transport mechanism of the drug from clopidogrel proniosomes is by diffusion [41].

Table 7: Kinetic parameters of clopidogrel proniosomes

\begin{tabular}{llll}
\hline Formula & Zero-order & First order & Higuchi model \\
\hline F1 & 0.987 & 0.970 & 0.998 \\
F2 & 0.991 & 0.990 & 0.998 \\
F3 & 0.991 & 0.990 & 0.999 \\
F4 & 0.992 & 0.995 & 0.999 \\
F5 & 0.995 & 0.990 & 0.999 \\
F6 & 0.993 & 0.983 & 0.998 \\
F7 & 0.997 & 0.977 & 0.998 \\
\hline
\end{tabular}

\section{Evaluation of the selected formula of clopidogrel proniosomes}

\section{Micromeritic properties}

Good flowability of powders is an important character in solid dosage forms to achieve better handling and processing. Results of micromeritic properties of maltodextrin and the selected proniosomal formulation were listed in table 8 . It was observed that the angle of repose of clopidogrel proniosomal powder $\left(31.67^{\circ} \pm 0.49^{\circ}\right)$ was lower than that of maltodextrin $\left(46.12^{\circ} \pm 0.53^{\circ}\right)$. Flowability is represented by the angle of repose $(\theta)$. A value of $\theta$ between $25-30^{\circ}$ indicates excellent flow, a value of $\theta$ between $31-35^{\circ}$ indicates good flow, a value of $\theta$ between $36-40^{\circ}$ indicates fair flow, a value of $\theta$ between $41-45^{\circ}$ indicates passable flow, a value of $\theta$ between $46-55^{\circ}$ indicates 'poor' flow and a value of $\theta$ higher than $56^{\circ}$ indicates 'very poor' flow [42]. Based on this, the flow of clopidogrel proniosomes was rated as good flow, whereas the flow of maltodextrin was rated as poor flow. These results showed that proniosomal formula is of good flowability that is higher than that of maltodextrin powder.

Table 8: Micromeritic properties of maltodextrin and selected proniosomal formula (F1)

\begin{tabular}{ll}
\hline Formulation & Angle of repose \\
\hline Maltodextrin & $46.12^{\circ} \pm 0.53^{\circ}$ \\
Proniosomal formula (F1) & $31.67^{\circ} \pm 0.49^{\circ}$ \\
\hline
\end{tabular}

${ }^{*}$ Data are expressed as mean $\pm \mathrm{SD}, \mathrm{n}=3$

\section{Photomicroscopic examination}

Examination of the chosen proniosomal formula under an optical microscope, fig. 2 showed that the surface of clopidogrel proniosomes was irregular due to a coating of the molecules of Span 60 and cholesterol over the surface of maltodextrin [15]. Moreover, proniosomes were progressively and rapidly converted to niosomes upon addition of the aqueous phase due to swelling of the bilayers and vesicles by an interaction of water with the hydrophilic groups of surfactant. The swelled bilayers tend to form spherical structures giving rise to multi-lamellar and multi-vesicular structures that are converted to unilamellar niosomal vesicles upon sonication.

Our results agree with those reported by Singh et al. (2012) [43].

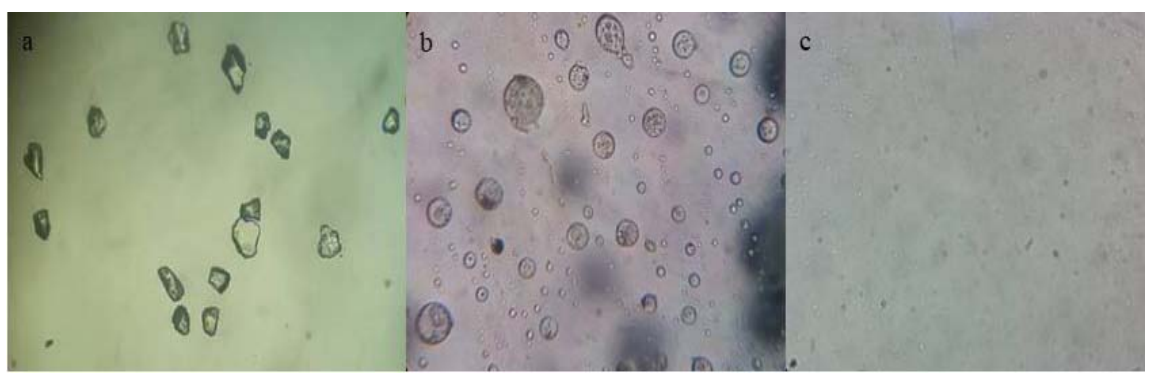

Fig. 2: Optical photomicrograph of (a) proniosomal clopidogrel powder (10x) (b) proniosomal clopidogrel moist powder before sonication $(40 \times)$, and (c) clopidogrel niosomes after sonication $(40 \times)$ 


\section{Scanning electron microscopy (SEM)}

The SEM micrograph of the chosen proniosomal formula is illustrated in fig. 3. It was observed that the niosomal vesicles formed by hydration of proniosomes were discrete and spherical in shape with sharp boundaries. This may be attributed to the fact that the non-ionic surfactants form a closed bilayer vesicle in water based on its amphoteric nature using some energy like physical agitation or heat [44]. Spherical shape of niosomes may be attributed to their tendency to minimize their surface free energy. That is in accordance with the results reported by Das and Palei (2011) [45].

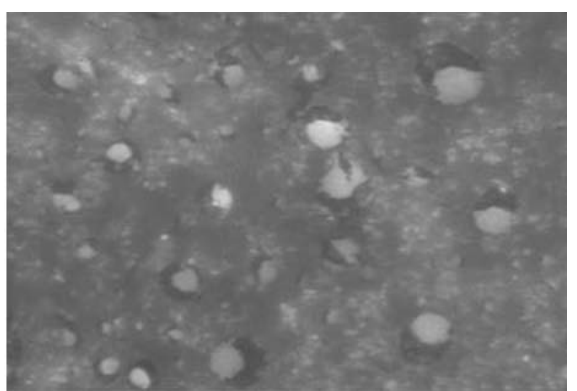

Fig. 3: Scanning electron micrograph of hydrated proniosomes of clopidogrel (F1)

\section{Vesicle size and zeta potential determination}

The particle size distribution of the chosen proniosomal formula showed unimodal normal symmetrical frequency distribution patterns, fig. 4 . The mean vesicle size of the hydrated clopidogrel proniosomes was $217.9 \mathrm{~nm}$. The polydispersity index, PDI, is an important parameter that describes the vesicle size distribution and it varies from 0.0 to 1.0 . As the PDI value is closer to zero, the more homogenous the vesicles size. PDI was 0.005 indicating a narrow and homogenous size distribution [46].

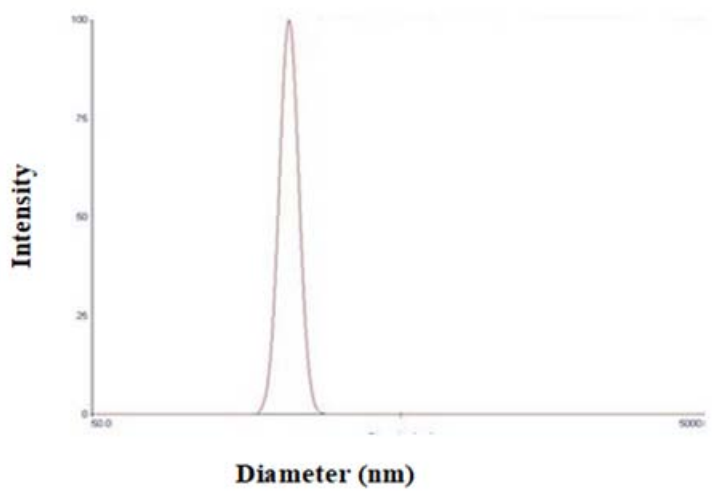

Fig. 4: Particle size distribution curve of clopidogrel proniosomal formula $(\mathrm{F} 1)$

The stability of colloidal dispersion is described by zeta potential. The colloidal dispersion that has large positive or negative zeta potential is considered to be stable. The chosen clopidogrel proniosomal formula has a positive zeta potential value $(+17.65 \mathrm{mv})$ indicating that the chosen proniosomal formula is stable, fig. 5. Zeta potential is a measure of the net charge of niosomes. This high charge on the vesicle surface produces repulsion between the vesicles that make them stable without agglomeration providing a uniformly distributed suspension [10]. The positive value of zeta potential could be attributed to the presence of the nitrogen atom in the structure of cationic clopidogrel bisulphate [47]. This positive charge dominates over cholesterol and the neutral charge of Span 60 Our results are in agreement with Sengodan et al. (2009)[13].

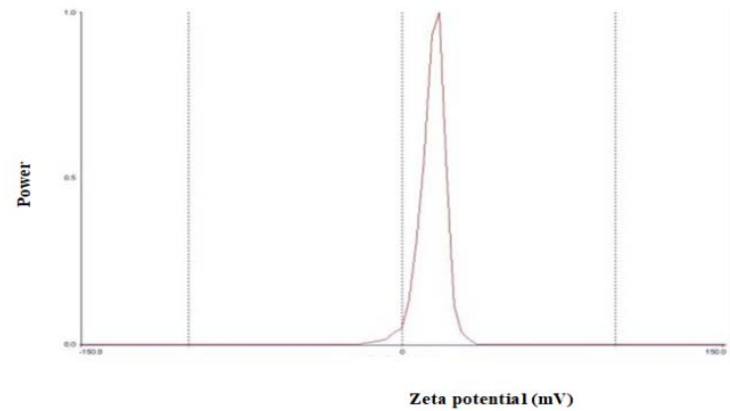

Fig. 5: Zeta potential distribution of clopidogrel proniosomal formula (F1)

\section{Fourier transform infrared spectroscopy (FTIR)}

The FTIR spectra of clopidogrel, Span 60, cholesterol, maltodextrin, drug-free proniosomes and the chosen clopidogrel proniosomal formula (F1) were illustrated in fig. 6. The FTIR spectrum of clopidogrel showed characteristic peaks of clopidogrel which were absorption band at $2544 \mathrm{~cm}^{-1}$ which is due to $\left(\mathrm{N}^{+}-\mathrm{H}\right), 1751 \mathrm{~cm}^{-1}$ ( $C=0$, stretching), $1190 \mathrm{~cm}^{-1}$ (C-O, stretching), $1030 \mathrm{~cm}^{-1}$ (C-O) [48]. Span 60 exhibited characteristic peaks at 3410 which is due to aliphatic O-H stretch, $2936 \mathrm{~cm}^{-1}$ (C-H stretch) and $1745 \mathrm{~cm}^{-1}$ (C =O stretch of ester). The characteristic peaks of cholesterol appeared at $3400 \mathrm{~cm}^{-1}$ (OH stretching) and the observed bands between 2800 $3000 \mathrm{~cm}^{-1}$ are due to asymmetric and symmetric stretching vibrations of $\mathrm{CH}_{2}$ and $\mathrm{CH}_{3}$ groups. [49]. FTIR spectrum of maltodextrin showed an absorption band at $3399 \mathrm{~cm}^{-1}$ for $\mathrm{OH}$ group, a strong broadband between $980 \mathrm{~cm}^{-1}$ and $1200 \mathrm{~cm}^{-1}$ which is the most characteristic band for polysaccharides. The peaks at $1152 \mathrm{~cm}^{-}$ 1 and $1018 \mathrm{~cm}^{-1}$ were attributed to C-0 stretching [50]. IR spectrum of plain proniosomes exhibited the characteristic peaks of cholesterol, Span 60 and maltodextrin with the reduced intensity that may be due to the formation of the lipid bilayer. FTIR spectrum of the selected proniosomal formula exhibited the characteristics peaks of clopidogrel that coffirmed the absence of any chemical interactions between clopidogrel and other excipients [12]. Reduced-intensity and minor shifting of the characteristic peaks of clopidogrel may be explained on the basis of formation of Van der Wall forces, hydrogen bonds or dipole-dipole interactions between clopidogrel and other proniosome contents leading to the formation of stable proniosomal vesicles with high entrapment efficiency of the drug [49].

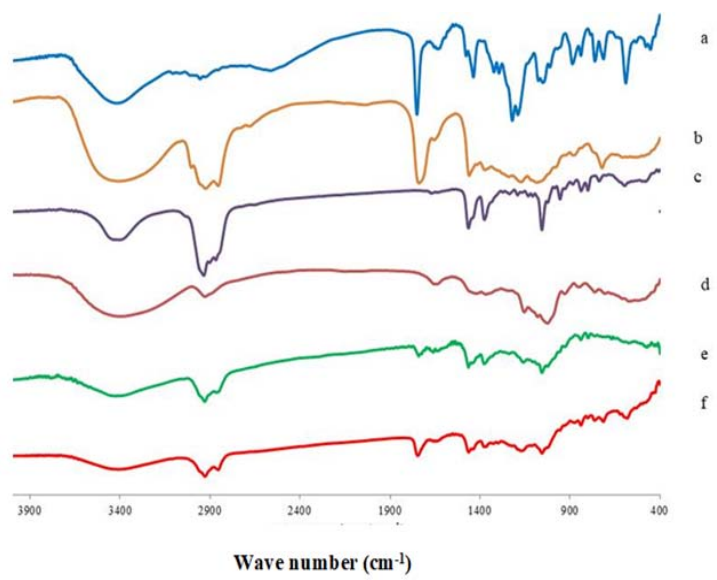

Fig. 6: FTIR spectrum of clopidogrel (a), Span 60 (b), cholesterol (c), maltodextrin (d), plain proniosomes (e) and the chosen clopidogrel proniosomal formula (f)

\section{Differential thermal analysis (DTA) study}

DTA could be used to detect the thermal behavior and physical state of drug. DTA thermograms of clopidogrel, Span 60, cholesterol, 
maltodextrin, plain (drug-free) proniosomes and the chosen proniosomal formula are presented in fig. 7. The DTA thermogram of clopidogrel showed a sharp endothermic peak at $179{ }^{\circ} \mathrm{C}$ which is corresponding to its melting point and indicated the crystallinity of clopidogrel [2]. Span 60, cholesterol and maltodextrin showed endothermic peaks at $54.4^{\circ} \mathrm{C}, 144.2{ }^{\circ} \mathrm{C}$ and $294.9^{\circ} \mathrm{C}$ corresponding to their transition temperatures, respectively [51, 52]. The plain proniosomes exhibited an appearance of a new endothermic peak at $191.1^{\circ} \mathrm{C}$. That may be explained on the basis of interaction of the proniosome components during the formation of the lipid bilayer [49]. The chosen proniosomal formula (F1) showed the shift of the endothermic peak of the lipid bilayer to $199^{\circ} \mathrm{C}$ and disappearance of the endothermic peak of clopidogrel. These findings are in accordance with results reported by Patil (2015) [53]. These findings might suggest a change of clopidogrel structure from crystalline to amorphous state due to high entrapment efficiency of clopidogrel into proniosomes [54]. That may be the cause of the enhanced dissolution of clopidogrel from proniosomes because amorphous state contains no crystal lattice interactions or bonds that need to be broken [55].

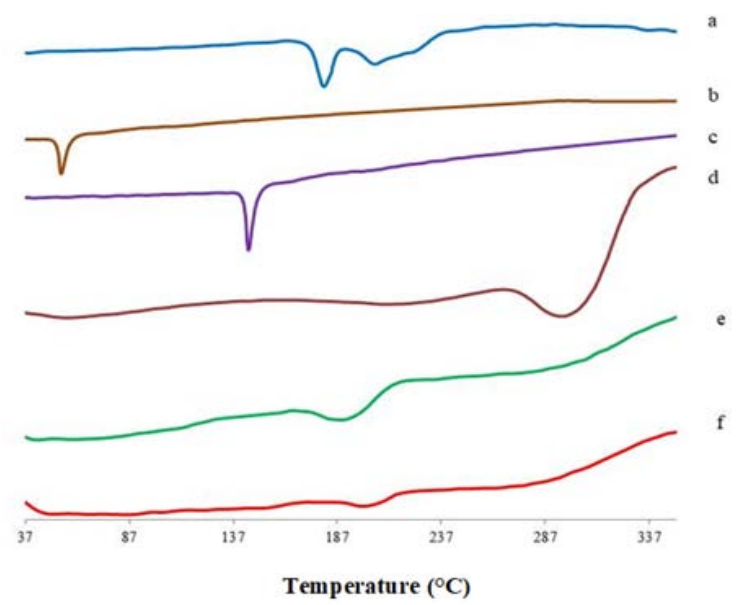

Fig. 7: DTA thermogram of clopidogrel (a), Span 60 (b), cholesterol (c), maltodextrin (d), plain proniosomes (e) and the chosen clopidogrel proniosomal formula (f)

\section{In vivo study}

The In vivo behavior of the chosen proniosomal formulation (F1) was studied by measuring antiplatelet activity in adult male mice using platelet aggregation inhibition study and INR Measurement.

\section{Effect of clopidogrel proniosomal formula (F1) on platelet aggregation}

The effect of the chosen clopidogrel proniosomal formula (F1) on platelet aggregation was measured as bleeding time and bleeding volume. Our results showed that clopidogrel proniosomal formula (F1) significantly $(\mathrm{p} \leq 0.001)$ increased the bleeding time $(6.82 \pm 1.4) \mathrm{min}$ compared to both control group (1.99 \pm 0.27$) \mathrm{min}$ as well as clopidogrel group $(3.32 \pm 0.33) \mathrm{min}$ after $1 \mathrm{~h}$ of treatment. The results obtained after $3 \mathrm{~h}$ of treatment further confirmed the inhibitory effect of the proniosomal formula on platelet aggregation. The bleeding time in mice treated with $\mathrm{F} 1$ reached up to $(9.860 \pm 1.710)$ min which was significantly $(\mathrm{P}<0.001)$ different from outcomes of control group $(2.05 \pm 0.37) \mathrm{min}$ and clopidogrel-treated group (5.11 \pm 0.54$) \mathrm{min}$, (fig. 8A).

Moreover, the bleeding volume $1 \mathrm{~h}$ after treatment with clopidogrel proniosomal formula (F1) $(0.22 \pm 0.019) \mathrm{ml}$ was significantly $(\mathrm{P}<0.001)$ greater than control group $(0.11 \pm 0.01) \mathrm{ml}$ and clopidogrel group $(0.17 \pm 0.02) \mathrm{ml}$. Similarly, after $3 \mathrm{~h}$ of treatment, the bleeding volume of mice treated with F1 $(0.31 \pm 0.04) \mathrm{ml}$ was significantly $(\mathrm{P}<0.001)$ higher than control group $(0.15 \pm 0.02) \mathrm{ml}$ and clopidogrel group $(0.21 \pm 0.04) \mathrm{ml}$ (fig. $8 \mathrm{~B})$.

\section{Effect of clopidogrel proniosomal formula (F1) on coagulation profile}

The effect of the chosen clopidogrel proniosomal formula (F1) on the coagulation profile was measured using coagulation markers such as prothrombin time and prothrombin activity as well as INR. The results of this study showed that clopidogrel as proniosomes was more potent compared to clopidogrel aqueous dispersion where $3 \mathrm{~h}$ post-treatment, clopidogrel proniosomal formula (F1) significantly $(\mathrm{P}<0.05)$ prolonged prothrombin time to $(15.5 \pm 0.57) \mathrm{min}$ and decreased prothrombin activity to $(62.35 \% \pm 5.28)$ and consequently increased the INR up to $(1.52 \pm 0.12)$ compared to plain clopidogrel suspension that showed $(14.17 \pm 0.36) \mathrm{min},(71.95 \% \pm 1.76)$ and $(1.33 \pm 0.05)$ for prothrombin time, prothrombin activity and INR respectively. The outcomes of the two groups were significantly $(\mathrm{P}<0.01)$ different from those obtained from a control group that showed prothrombin time, prothrombin activity and INR equal to (12.64 $\pm 0.71 \mathrm{~min}, 82.64 \% \pm 4.6,1.15 \pm 0.07$ ) respectively (fig. 9).

The above data agree with results reported by Karabulut et al.(2004)[56]. Moreover, from the above results, it is clear that the formulation of clopidogrel as proniosomes improved the antiplatelet effect of clopidogrel. That may be attributed to the enhancement of solubility and bioavailability of clopidogrel following formulation as proniosomes. These results are in accordance with Wen et al. (2011) [57] and Sengodan et al.(2009)[13] who reported that the prepared proniosomal formulation showed higher pharmacological effect than the plain drug. In addition, Ali et al.(2015) observed that liposomes of clopidogrel were more effective in the inhibition of platelet aggregation than orally administered clopidogrel [30]. Therefore, Proniosomes are emerging strategy for more effective drug delivery [58].
$\mathbf{A}$
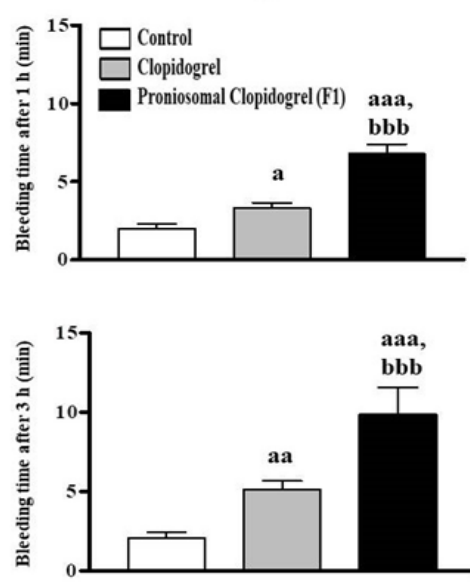

B

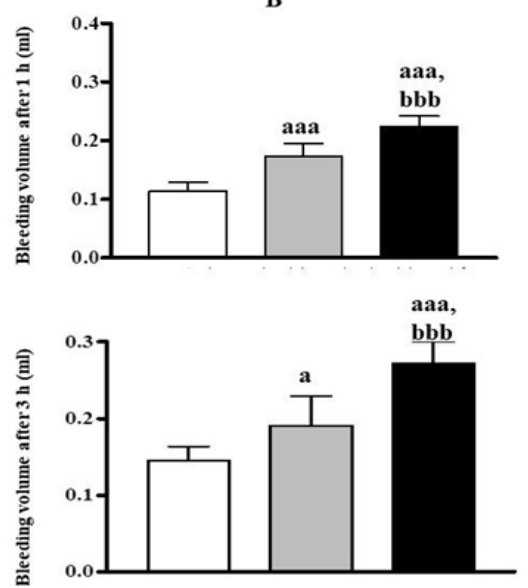

Fig. 8: Effect of clopidogrel proniosomal formula (F1) on platelet aggregation, "values of test group are compared with control group: a (p $\leq 0.05)$, aa ( $\leq 0.01)$, aaa $(p \leq 0.001)$ and compared with Clopidogrel group: $b(p \leq 0.05)$, bb $(p \leq 0.01)$, bbb $(p \leq 0.001)$, ${ }^{*}$ Data are expressed as mean $\pm S D, n=5$ 


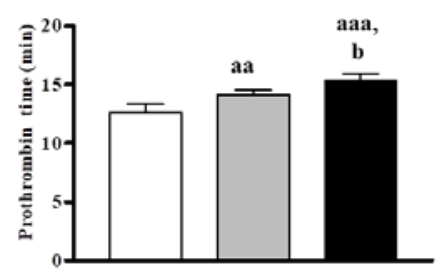

B

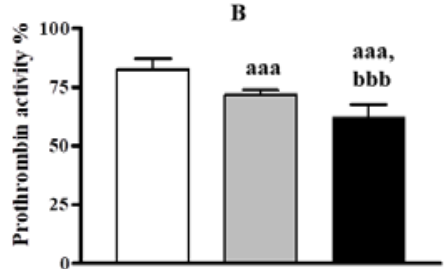

C
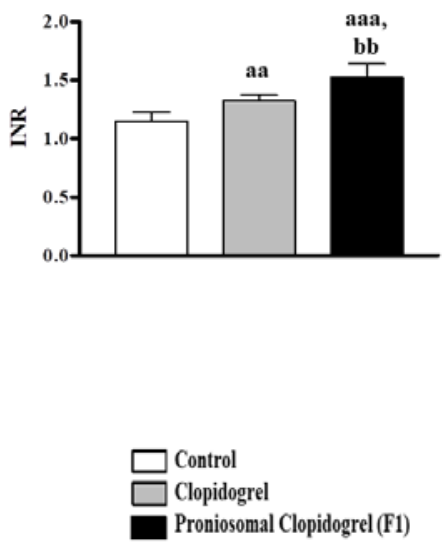

Fig. 9: Effect of clopidogrel proniosomal formula on coagulation profile, *values of test group are compared with control group a (p $\leq$ $0.05)$, aa ( $p \leq 0.01)$, aaa $(p \leq 0.001)$ and compared with Clopidogrel group $b(p \leq 0.05)$, bb $(p \leq 0.01), b b b(p \leq 0.001)$, ${ }^{*}$ Data are expressed as mean $\pm S D, n=5$

\section{CONCLUSION}

The present study deals with developing clopidogrel proniosomes. Clopidogrel-based proniosomes were successfully prepared as freeflowing powders with high entrapment efficiency in the range of $83.04 \pm 1.99$ to $90.14 \pm 0.30$. The proniosomal formulations showed higher dissolution profile than the plain drug. F1 (clopidogrel proniosomes prepared with cholesterol and Span 60 in 40: 210 molar ratio) showed the highest in vitro release over other proniosomal formulations. F1 was found to be free-flowing powder of good flowability that is higher than that of maltodextrin powder. The niosomal vesicles formed by hydration of F1 proniosomes were spherical in shape with mean vesicle size of $217.9 \mathrm{~nm}$ with zeta potential value $(+17.65 \mathrm{mv})$. FTIR study con firmed the absence of any chemical interactions between clopidogrel and other excipients. DTA study showed a change of clopidogrel structure from crystalline to an amorphous state. In vivo test showed that clopidogrel proniosomal formula enhanced the antiplatelet activity of clopidogrel. This approach could be promising in enhancing the dissolution, bioavailability, and efficacy of clopidogrel as well as to decrease its adverse effects.

\section{AUTHORS CONTRIBUTIONS}

All authors have contributed equally

\section{CONFLICT OF INTERESTS}

All authors have declared no conflict of interest

\section{REFERENCES}

1. Sanjaymitra PVSS, Ganesh GNK. Dissolution and solubility enhancement strategies: current and novel prospectives. J Crit Rev 2018;5:1-10.

2. Jassim ZE, Hussein AA. Formulation and evaluation of clopidogrel tablet incorporating drug nanoparticles. Iran J Pharm Sci 2014;6:838-51.

3. Dua JS, Rana AC, Bhandari AK. Liposome: methods of preparation and applications. Int J Pharm Stud Res 2012;3:14-20.

4. Sharma Vijay K, Mishra DN, Sharma AK, Srivastava B. Liposomes: present prospective and future challenges. Int J Curr Pharm Rev Res 2010;1:6-16.

5. Ulrich AS. Biophysical aspects of using liposomes as delivery vehicles. Biosci Rep 2002;22:129-50.

6. Kumar D, Sharma D, Singh G, Singh M, Rathore MS. Lipoidal soft hybrid biocarriers of supramolecular construction for drug delivery. ISRN Pharm 2012. http://dx.doi.org/10.5402/ 2012/474830.

7. Yadav K, Yadav D, Saroha K, Nanda S, Mathur P, Syan N. Proniosomal gel: a provesicular approach for transdermal drug delivery. Der Pharm Lett 2010;2:189-98.
8. Yasam VR, Jakki SL, Natarajan J, Kuppusamy G. A review on novel vesicular drug delivery: proniosomes. Drug Delivery 2014;21:243-9.

9. Solanki A, Parikh J, Parikh R. Preparation, characterization, optimization, and stability studies of aceclofenac proniosomes. Iran J Pharm Res 2008;7:237-46.

10. Samy AM, Ramadan AA, Abu El-Enin ASM, Mortagi YIM. Formulation and optimization of itraconazole proniosomes using box behnken design. Int J Appl Pharm 2018;10:41-51.

11. Porter CJH, Trevaskis NL, Charman WN. Lipids and lipid-based formulations: optimizing the oral delivery of lipophilic drugs. Nat Rev Drug Discovery 2007;6:231-48.

12. Boddu M, Choppari V, Rapalli VK, Badam M. Formulation and evaluation of proniosomes of felodipine. Drug Des 2017;6:154.

13. Sengodan T, Sunil B, Vaishali R, Chandra RJ, Nagar S, Nagar 0 . Formulation and evaluation of maltodextrin based proniosomes loaded with indomethacin. Int J PharmTech Res 2009;1:517-23.

14. Marwa HA, Omaima AS, Hanaa AE, Hanan ME. Optimizing proniosomes for controlled release of ketoprofen using a boxbehnken experimental design. Int J Pharm Sci Res 2011;2:2195.

15. Chauhan MK, Sahoo PK, Rawat AS, Duggal D, Kandwal M, Sandal N. Formulation, characterization and in vitro evaluation of tactically engineered proniosomes for successful oral delivery of ramipril. Der Pharm Lett 2015;7:93-7.

16. El Maghraby GM, Ahmed AA, Osman MA. Penetration enhancers in proniosomes as a new strategy for enhanced transdermal drug delivery. Saudi Pharm J 2015;23:67-74.

17. Moore JW, Flanner HH. Mathematical comparison of curves with an emphasis on in vitro dissolution profile. Pharm Technol 1996;20:64-74.

18. Samy AM, Ghorab MM, Shadeed SG, Mazyed EA. Formulation and evaluation of different transdermal drug delivery systems of ketoprfen. Int J Pharm Pharm Sci 2013;5 Suppl 2:600-7.

19. Nyol S, Gupta MM. Immediate drug release dosage form: a review. J Drug Delivery Ther 2013;3:155-61.

20. AhmedIbrahiem MM. Proniosomal oral tablets for controlled delivery and enhanced pharmacokinetic properties of Acemetacin. AAPS 2014;16:375-83.

21. Sivannarayana P, Rani AP, Saikishore V, Venu Babu C, Sri Rekha $V$. Transfersomes: ultra deformable vesicular carrier systems in transdermal drug delivery system. Res J Pharm Dos Forms Technol 2012;4:243-5.

22. Das B, Sen SO, Maji R, Nayak AK, Sen KK. Transferosomal gel for transdermal delivery of risperidone: formulation optimization and ex vivo permeation. J Drug Delivery Sci Technol 2017;38:59-71.

23. Gupta A, Prajapati SK, Balamurugan M, Singh M, Bhatia D. Design and development of a proniosomal transdermal drug delivery system for captopril. Trop J Pharm Res 2007;6:687-93. 
24. Maheswari U, Mullaicharam AR. Development and in vitro evaluation of nanosuspension formulation containing acyclovir for the treatment of ocular infections. Res J Pharm Biol Chem Sci 2013;4:463-80.

25. Trivedi MK, Branton A, Trivedi D, Nayak G, Mishra R, Jana S. Characterization of physical, thermal and spectral properties of biofield treated 2-aminopyridine. Sci J Anal Chem 2015;3:127-34.

26. Eid RK, Essa EA, El Maghraby GM. Essential oils in niosomes for enhanced transdermal delivery of felodipine. Pharm Dev Technol 2018;23:1-9.

27. Kilkenny C, Browne WJ, Cuthill IC, Emerson M, Altman DG. Improving bioscience research reporting: the ARRIVE guidelines for reporting animal research. PLoS Biol 2010;8:e1000412.

28. 2010/63/EU EU directive. Directive 2010/63/EU of the European Parliament and of the Council of 22 September 2010 on the protection of animals used for scientific purposes. Off J Eur Union L 2010;276:33-79.

29. de Vries JW, Schnichels S, Hurst J. DNA nanoparticles for ophthalmic drug delivery. Biomaterials 2018;157:98-106.

30. Ali SM, Sheikh S, Ahmad A, Moghis U. Pre-clinical and phase i clinical study of clopidogrel lipid suspension: intravenously injected formulation results in the faster onset of action and dose-dependent inhibition of platelet aggregation. J Pharmacol Clin Toxicol 2015;3:1-8.

31. Murad JP, Espinosa EVP, Ting HJ, Khasawneh FT Characterization of the in vivo antiplatelet activity of the antihypertensive agent losartan. J Cardiovasc Pharmacol Ther 2012;17:308-14

32. Foerch C, Arai K, Jin G. Experimental model of warfarinassociated intracerebral hemorrhage. Stroke 2008;39:3397404.

33. Lemini C, Jaimez R, Franco Y. Gender and inter-species influence on coagulation tests of rats and mice. Thromb Res 2007;120:415-9.

34. Gurrapu A, Jukanti R, Bobbala SR, Kanuganti S, Jeevana JB. Improved oral delivery of valsartan from maltodextrin based proniosome powders. Adv Powder Technol 2012;23:583-90.

35. Nii T, Ishii F. Encapsulation efficiency of water-soluble and insoluble drugs in liposomes prepared by the microencapsulation vesicle method. Int J Pharm 2005;298:198-205.

36. Singh $\mathrm{CH}$. Formulation, characterization, stability and in vitro evaluation of nimesulide niosomes. Pharmacophore 2011;2:131-48.

37. Sankar V, Ruckmani K, Durga S, Jailani S. Proniosomes as drug carriers. Pak J Pharm Sci 2010;23:103-7.

38. Ibrahim MM, Tawfique SAH, Mahdy MM. Liposomal diltiazem $\mathrm{HCl}$ as ocular drug delivery system for glaucoma. Drug Dev Ind Pharm 2014;40:765-73.

39. Mokhtar ASZ and M. Multivariate optimization of formulation variables influencing flurbiprofen proniosomes characteristics. J Pharm Sci 2011;100:2212-21.

40. Asthana GS, Sharma $\mathrm{PK}$, Asthana A. In vitro and in vivo evaluation of niosomal formulation for controlled delivery of clarithromycin. Scientifica (Cairo) 2016. Doi: 10.1155/ 2016/6492953.
41. Mokale VI, Patil HI, Patil AP, Shirude PR, Naik JB. Formulation and optimisation of famotidine proniosomes: an in vitro and ex vivo study. J Exp Nanosci 2016;11:97-110.

42. USP30-NF25, U. P., US Pharmacopoeial Convention, Inc, Rock. USA; 2007.

43. Singh S, Trivedi S, Jain S. Design and development of proniosome based transdermal delivery of ondansetron hydrochloride. Int J Pharm Biol Res 2012;3:191-201.

44. Kazi KM, Mandal AS, Biswas N. Niosome: a future of targeted drug delivery systems. J Adv Pharm Technol Res 2010;1:37480.

45. Das MK, Palei NN. Sorbitan ester niosomes for topical delivery of rofecoxib. Indian J Exp Biol 2011;49:438-45.

46. Keservani RK, Sharma AK, Jain S. Effect of different process variables on the preparation of baclofen niosomes. Int J Univ Pharm Life Sci 2011;1:301-10.

47. Balasubramaniam J, Bindu K, Rao VU, Ray D, Haldar R, Brzeczko AW. Effect of superdisintegrants on a dissolution of cationic drugs. Dissolution Technol 2008;15:18-25.

48. Patel P. Design and development of self microemulsifying drug delivery system of clopidogrel bisulphate. Int J Pharmamedix India 2013;1:539-53.

49. El-Sayed MM, Hussein AK, Sarhan HA, Mansour HF. Flurbiprofen-loaded niosomes-in-gel system improves the ocular bioavailability of flurbiprofen in the aqueous humor. Drug Dev Ind Pharm 2017;43:902-10.

50. Sun P, Yang HJ, Wang YQ, Liu KZ, Xu YW. Lipase-catalyzed synthesis and characterization of stearic acid dextrin ester. Res Heal Nutr 2013;1:7-11.

51. Rahman SA, Abdelmalak NS, Badawi A, Elbayoumy T, Sabry N, Ramly AEl. Formulation of tretinoin-loaded topical proniosomes for treatment of acne: in vitro characterization, skin irritation test and comparative clinical study. Drug Delivery 2015;22:731-9.

52. Das S. Study of decomposition behaviour of binders and the effect of binder type on strength and density of alumina samples, BTech Thesis, Department of Ceramic Engineering, National Institute of Technology Rourkela; 2011.

53. Patil BA. Formulation and development of industry feasible proniosomal transdermal drug delivery system of granisetron hydrochloride. Asian J Pharm 2015;9:113-9.

54. Patil HN, Hardikar SR, Bhosale AV. Formulation, development and evaluation of proniosomal gel of carvedilol. Int J Pharm Pharm Sci 2012;4:191-7.

55. Sahoo RK, Biswas N, Guha A, Sahoo N, Kuotsu K. Development and in vitro/in vivo evaluation of controlled release provesicles of a nateglinide-maltodextrin complex. Acta Pharm Sin B 2014;4:408-16

56. Karabulut H, Toraman F, Evrenkaya S, Goksel O, Tarcan S, Alhan C. Clopidogrel does not increase bleeding and allogenic blood transfusion in coronary artery surgery. Eur J CardioThoracic Surg 2004;25:419-23.

57. Wen MM, Farid RM, Kassem AA. Nano-proniosomes enhancing the transdermal delivery of mefenamic acid. J Liposome Res 2014;24:280-9.

58. Vasistha P, Ram A. Non-ionic provesicular drug carrier: an overview. Asian J Pharm Clin Res 2013;6 Suppl 1:38-42. 